examination showed delayed gastric emptying with a lesser curve gastric ulcer. Acid secretory studies showed no response to insulin, indicating a complete vagotomy. At reoperation, eight months after the first operation, a lesser curve gastric ulcer was present but no duodenal ulcer. He is now well after antrectomy.

Case 3.-An insulin test was negative three months after vagotomy in a man aged 37. After one year he developed epigastric pain and vomiting and barium meal examination showed a lesser curve gastric ulcer with normal gastric emptying. The ulcer was confirmed by gastroscopy. Conservative treatment of the ulcer was undertaken and further gastroscopy showed that the ulcer was healing. Fourteen months after the operation and two months after the development of a gastric ulcer a barium meal examination showed an apparently normal stomach which still emptied normally. He was then symptom-free.

\section{Discussion}

The idea of treating patients with duodenal ulceration by vagotomy without a drainage operation is attractive and has been the goal of many surgeons. Dragstedt and Owens (1943) advocated vagal section for duodenal ulcer; a truncal vagotomy was the operation first used. It soon became clear that there were many complications resulting from gastric retention (Jackson, 1948; Slaney et al., 1956), and Dragstedt et al. (1947) were quick to point out that most patients with duodenal ulcer required some form of drainage operation in addition to vagotomy.

Burge et al. (1969) suggested that selective vagotomy would retain sufficient innervation to the prepyloric and pyloric regions of the stomach via the pyloric branch of the anterior vagus and so allow normal gastric emptying to occur. Nevertheless, Franksson (1948) had earlier attempted to use bilateral selective vagotomy without drainage, but because of the complications of gastric retention, even in patients with no ulcer stenosis, he later abandoned the operation (Shiina and Griffiths, 1969). De Miguel (1970) treated 20 duodenal ulcer patients without any evidence of stenosis by selective vagotomy without drainage.
Two years after operation about half the patients had some gartric retention on barium meal examination.

Experimental evidence of gastric retention after selective vagotomy in the dog is provided by Shiina and Griffiths (1969). Two to three weeks after operation barium studies showed severe gastric stasis with retention of barium for up to 24 hours. Eight weeks after operation the gastric stasis had only partially improved.

Burge et al. (1969) reported good clinical results after selective vagotomy without drainage and advocated the operation in patients with duodenal ulcer without stenosis. They state that the flatulence and foul eructations which may occur soon after operation, and are associated with a large nine-hour residue on a "special" barium meal, disappear with time. It seems likely that the effects they describe soon after operation are due to the same delay of gastric emptying that we have measured at three months after operation, and many of our patients may later improve as theirs seem to have done. Nevertheless, in one of our patients gastric stasis persisted at one year and in others gastric ulceration had developed in association with stasis. Therefore, with the technique of selective vagotomy that we have used, some form of gastric drainage procedure should always be added.

Requests for reprints should be sent to Mr. J. Alexander Williams.

\section{References}

Burge, H., MacLean, C., Stedeford, R., Pinn, G., and Hollanders, D. (1969). British Medical fournal, 3, 690 .

De Miguel, J. (1970). Cirugia Española, 24, 121.

Dragstedt, L. R., Harper, P. V., jun., Tovee, E. B., and Wood, E. R. (1947). Annals of Surgery, 126, 687.

Dragstedt, L. R., and Owens, F. M. (1943). Proceedings of the Society of Experimental Biology and Medicine, 53, 152.

Franksson, C. (1948). Acta Chirurgica Scandinavica, 96, 409.

George, J. D. (1968). Gut, 9, 237.

Jackson, R. G. (1948). Archives of Surgery, 57, 333.

Shiina, E., and Griffiths, C. A. (1969). Annals of Surgery, 169, 326.

Slaney, G., Bevan, P. G., and Brooke, B. N. (1956). Lancet, 2, 221.

\title{
Effects of Salbutamol and Isoprenaline/Phenylephrine in Reversible Airways Obstruction
}

\author{
R. J. ALLIOTT, \\ B. D. LANG, \\ D. R. W. RAWSON, \\ W. J. H. LECKIE
}

British Medical fournal, 1972, 1, 539-542

\begin{abstract}
Summary
Ventolin (salbutamol) and Medihaler-Duo (isoprenaline/ phenylephrine combination) standard pressurized inhalers were used to administer doses of two or six "puffs" to 16 patients with known reversible airways obstruction. The doses were administered in random order over two days. Both the Ventolin and Medihaler-Duo inhalers substantially increased $\mathrm{FEV}_{1}$, but in the doses used salbutamol was more effective than isoprenaline/phenylephrine $(P<0.01)$. There was no significant difference between two and six puffs of salbutamol, though there seemed to be an advantage of six puffs of isoprenaline/ phenylephrine over two puffs $(P<0.05)$. Adrenaline $(1 / 1,000) 0.5 \mathrm{ml}$ and atropine $0.6 \mathrm{mg}$ produced similar increases in $\mathrm{FEV}_{1}$ to those produced by salbutamol.
\end{abstract}

County Hospital, Hereford

R. J. ALLIOTT, M.B., CH.B., Senior House Officer, General Medicine

B. D. LANG, S.R.N., Ward Sister

D. R. W. RAWSON, F.I.M.L.T., Chief Technician, Biochemistry Department W. J. H. LECKIE, M.D., F.R.C.P., Consultant Physician
The $\mathrm{PaO}_{2}$ fell more than $5 \mathrm{~mm} \mathrm{Hg}$ in three patients after salbutamol and in three after isoprenaline/phenylephrine. There was no significant fall in mean $\mathrm{PaO}_{2}$ in any of the treatment groups. It is concluded that the Ventolin inhalant, administered in the conventional dose of two puffs, is as effective a bronchodilator as subcutaneous adrenaline and atropine, is more effective than the MedihalerDuo, and is without detectable side effects.

\section{Introduction}

This investigation was prompted by a desire to know whether the conventional doses of salbutamol and isoprenaline/phenylephrine mixture produced a maximal bronchodilator response, and if not whether there were any contraindications to higher dosage. Salbutamol is thought to have minimal $\beta 1$-adrenergic effect (Brittain et al., 1968; Kennedy and Simpson, 1969; Palmer and Diament, 1969; Warrell et al., 1970) but other reports (Bass et al., 1969; Chapman, 1969; Hume, 1970) have shown a fall in $\mathrm{PaO}_{2}$ after its use in some patients. In contrast, this has not been found to happen with a phenylephrine/isoprenaline mixture (Chapman, 1969; Harris, 1970; Hume, 1970). Phenylephrine 
is a sympathomimetic amine acting on $\alpha$-receptors. It is thought to protect against the non-selective pulmonary vasodilatation occurring with 32 -stimulators and, in addition, to aid bronchodilatation and delay isoprenaline absorption by vasoconstriction in the bronchial mucosa (Cohen, 1962; Goldfarb and Romanoff, 1962; Kallós and Kallós-Deffner, 1963; Cohen and Hale, 1965; Zamel et al., 1966). Comparing the bronchodilator action of several commercially produced inhalants, Freedman et al. (1968) considered that the efficacy of those containing isoprenaline was related to the dose of this drug administered. The MedihalerDuo, which delivers $160 \mu \mathrm{g}$ of isoprenaline per "puff" was found to be considerably less effective as a bronchodilator than the Medihaler Iso Forte, which delivers $400 \mu \mathrm{g}$.

We therefore decided to compare two and six puffs of the Ventolin inhalant (salbutamol $100 \mu \mathrm{g}$ per puff) with two and six puffs of the Medihaler-Duo (isoprenaline hydrochloride $160 \mu \mathrm{g}$ and phenylephrine bitartrate $240 \mu \mathrm{g}$ per puff).

There has been a suggestion (Altounyan, 1964; Crompton, 1968) that as good a bronchodilator response to atropine as to adrenaline is found more commonly in bronchitic than asthmatic subjects. Tests to these drugs were therefore included in the investigation in case some correlation between individual patient's responses to adrenaline and atropine and the inhalants might be revealed.

\section{Patients and Methods}

Sixceen patients with obstructive airways disease whose $\mathrm{FEV}_{1}$ was increased by $15 \% 20$ minutes after the subcutaneous administration of $0.5 \mathrm{ml}$ of $1 / 1,000$ adrenaline or $0.6 \mathrm{mg}$ of atropine were selected for investigation. Of these, 10 were considered to be bronchitic according to the Medical Research Council (1965) definition and six were clinically asthmatics. None had other respiratory disease or overt heart disease. In view of the theoretical possibility of adrenaline acutely increasing cardiac work and of phenylephrine increasing pulmonary vascular resistance (Horvath and Knapp, 1954; Aviado and Schmidt, 1957), an electrocardiogram and a chest radiograph were taken before the investigation and patients excluded if there was any evidence of pulmonary hypertension or cardiac ischaemia. Sputum was mucoid on entry, and oxytetracycline was administered routinely over the three days of the investigation. Patients taking corticosteroids were excluded and no other bronchodilator was used during the investigation or for 12 hours preceding it.

On Day $10.5 \mathrm{ml}$ of $1 / 1,000$ adrenaline and $0.6 \mathrm{mg}$ of atropine were administered subcutaneously in random order, one in the morning and the other in the afternoon, separated by between four and six hours. A similar time schedule was adopted for Days 2 and 3, when two and six puffs of salbutamol and two and six puffs of isoprenaline/phenylephrine were administered, again randomized in Latin square pattern. Personnel operating the inhalers, which were the standard Ventolin (salbutamol) and Medihaler-Duo (isoprenaline/phenylephrine) pressurized inhalers, were trained medical or nursing staff and were constant, as were the observers, for each patient. Neither the dose nor the drug given was known to the observers recording pulse, blood pressure, $\mathrm{FEV}_{1}, \mathrm{FVC}$, and arteriolized capillary $\mathrm{PaO}_{2}$ and $\mathrm{PaCO}_{2}$. The patient was obviously aware of the inhalant dose but not of the drug. Recordings were made immediately before and 20 minutes after each dose.

$\mathrm{FEV}_{1}$ and FVC were obtained from the best of three attempts with the McDermott dry spirometer. Each patient with obstructive airways disease has a range over which sensitivity to bronchodilators varies (Hume and Gandevia, 1957). Also potential for improvement can be limited by a high pretreatment $\mathrm{FEV}_{1}$. Therefore, to allow fair comparison of recordings the FEV range found during the investigation was divided into five. Any measurement of $\mathrm{FEV}_{1}$ change in a patient with a pretreatment level in the upper two-fifths of the scale was discarded and comparison made between the remainder. These patients were not excluded from aspects of the investigation not related to change in $\mathrm{FEV}_{1}$. Scoring the remaining fifths 1, 2, and 3 allowed numerical comparison of pretreatment $\mathrm{FEV}_{1}$ values for each group. Pulse and blood pressure were recorded at rest reclining in bed. Arteriolized capillary oxygen and carbon dioxide tensions were estimated by a method previously validated (Attwood et al., 1970) and carried out by one of us (D.R.W.R.). Throughout the remainder of the paper the number of puffs administered is registered in parentheses after the type of inhalant administered; thus salbutamol (2) equals two puffs of Ventolin inhalant.

The paired $t$ test was used to assess significance.

\section{Results}

All 16 patients completed the investigation. Fourteen out of 96 ventilatory function results were excluded because the pretreatment values were at the 4 or 5 level-that is, the upper two-fifths of their $\mathrm{FEV}_{1}$. The mean scores for pretreatment $\mathrm{FEV}_{1}$ levels for the inhalants showed no significant differences and these groups are comparable in this respect.

The mean pretreatment levels for adrenaline and atropine were significantly higher, though it is considered unlikely that the degree of difference could have any effect on the results (Table I). The effects of adrenaline, atropine, salbutamol (2) and (6), and isoprenaline/phenylephrine (2) and (6) on dynamic lung volumes, blood gases, pulse rate, and blood pressure are shown in Table II.

TABLE I-Comparison of Pretreatment FEV according to Treatment Groups

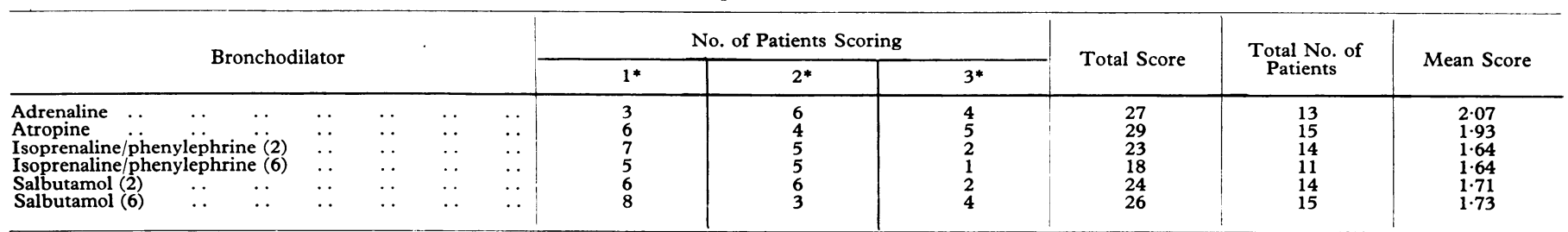

* The range of pretreatment $\mathrm{FEV}_{1}$ values was divided into five equal parts; these scores refer to the lower three-fifths of the pretreatment $\mathrm{FEV} \mathrm{i}_{1}$ scale (see text).

TABLE II-Comparison between Mean Change ( \pm S.D.) in FEV and FVC (\%) and in Arterial Blood Gas Tensions (mm Hg), Pulse Rate (beats/min), and Blood Pressure (mm Hg) in 16 Asthmatic Subjects* after Adrenaline, Atropine, Isoprenaline/Phenylephrine, and Salbutamol

\begin{tabular}{|c|c|c|c|c|c|c|c|c|}
\hline Drug/Dose & & ${ }^{*} \mathrm{FEV}_{1}$ & ${ }^{*} \mathrm{FVC}$ & Pulse & $\mathrm{PaO}_{2}$ & $\mathrm{PaCO}_{2}$ & Systolic B.P. & Diastolic B.P. \\
\hline 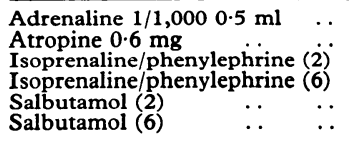 & $\begin{array}{l}\cdots \\
\because \\
\cdots \\
\cdots \\
\cdots\end{array}$ & $\begin{array}{l}23 \cdot 4( \pm 16 \cdot 0) \\
24 \cdot 0( \pm 20 \cdot 2) \\
12 \cdot 3( \pm 8 \cdot 8) \\
16 \cdot 8( \pm 14 \cdot 9) \\
24 \cdot 0( \pm 15 \cdot 5) \\
26 \cdot 0( \pm 17 \cdot 2)\end{array}$ & $\begin{array}{l}18 \cdot 2( \pm 12 \cdot 8) \\
20 \cdot 7( \pm 14 \cdot 1) \\
11 \cdot 9( \pm 10 \cdot 2) \\
18 \cdot 2( \pm 15 \cdot 6) \\
16 \cdot 1( \pm 15 \cdot 0) \\
17 \cdot 4( \pm 12 \cdot 8)\end{array}$ & $\begin{array}{l}+4.9( \pm 7.5) \\
+2.8( \pm 7.4) \\
+0.5( \pm 4.7) \\
-0.4( \pm 8 \cdot 8) \\
-1.6( \pm 6.4) \\
+5.0( \pm 6.1)\end{array}$ & $\begin{array}{r}0.0( \pm 4.7) \\
-0.2( \pm 4.8) \\
-0.6( \pm 4.4) \\
-0.4( \pm 3.9) \\
-0.9( \pm 4.3) \\
-0.6( \pm 3.2)\end{array}$ & $\begin{array}{l}-1.0( \pm 2.6) \\
+0.2( \pm 2.9) \\
+0.1( \pm 2.2) \\
-0.2( \pm 1.9) \\
-0.3( \pm 3.1) \\
+0.3( \pm 3.1)\end{array}$ & $\begin{array}{l}+3 \cdot 1( \pm 11 \cdot 3) \\
-6 \cdot 3( \pm 14 \cdot 3) \\
-1 \cdot 3( \pm 11 \cdot 5) \\
-3 \cdot 4( \pm 11 \cdot 8) \\
-5 \cdot 3( \pm 11 \cdot 1) \\
-1 \cdot 3( \pm 13 \cdot 0)\end{array}$ & $\begin{array}{l}-4 \cdot 7( \pm 7 \cdot 6) \\
-4 \cdot 7( \pm 9 \cdot 6) \\
-1 \cdot 3( \pm 9 \cdot 1) \\
-0 \cdot 6( \pm 9 \cdot 0) \\
-4 \cdot 7( \pm 7 \cdot 1) \\
-1 \cdot 3( \pm 8 \cdot 5)\end{array}$ \\
\hline
\end{tabular}

-Excludes patients whose pretreatment $\mathrm{FEV}_{1}$ was in the upper two-fifths of their $\mathrm{FEV}_{1}$ range during the investigation. 
TABLE III-Actual Change in $\mathrm{PaO}_{2}(\mathrm{~mm} \mathrm{Hg})$ in Each Patient for Each Drug/Dose Administration

\begin{tabular}{|c|c|c|c|c|c|c|}
\hline \multirow{2}{*}{ Case No. } & \multirow{2}{*}{$\begin{array}{c}\text { Adrenaline } 1 / 1,000 \\
0.5 \mathrm{ml}\end{array}$} & \multirow{2}{*}{$\begin{array}{l}\text { Atropine } \\
0.6 \mathrm{mg}\end{array}$} & \multicolumn{2}{|c|}{ Isoprenaline/Phenylephrine } & \multicolumn{2}{|c|}{ Salbutamol } \\
\hline & & & 2 Puffs & 6 Puffs & 2 Puffs & 6 Puffs \\
\hline $\begin{array}{r}1 \\
2 \\
3 \\
4 \\
5 \\
6 \\
7 \\
8 \\
9 \\
10 \\
11 \\
12 \\
13 \\
14 \\
15 \\
16\end{array}$ & $\begin{array}{l}-4 \\
+5 \\
-3 \\
+3 \\
+8 \\
-4 \\
+2 \\
+2 \\
-5 \\
-7 \\
+9 \\
+3 \\
+2 \\
-6 \\
-2 \\
-2\end{array}$ & $\begin{array}{l}+2 \\
+4 \\
-9 \\
+2 \\
+2 \\
-2 \\
+5 \\
-6 \\
-7 \\
-3 \\
+8 \\
+5 \\
-2 \\
-6 \\
+2 \\
+1\end{array}$ & $\begin{array}{l}-7 \\
-4 \\
-5 \\
+10 \\
-1 \\
-2 \\
-2 \\
-2 \\
-1 \\
-1 \\
-1 \\
-3 \\
+4 \\
0 \\
+6 \\
-1\end{array}$ & $\begin{array}{r}-4 \\
-7 \\
-6 \\
+4 \\
0 \\
+4 \\
-2 \\
+3 \\
+2 \\
-5 \\
-3 \\
-3 \\
+4 \\
+4 \\
+4 \\
-1\end{array}$ & $\begin{array}{l}+3 \\
-1 \\
-6 \\
+2 \\
+10 \\
-2 \\
-5 \\
+4 \\
-3 \\
-5 \\
-5 \\
-7 \\
+2 \\
0 \\
+1 \\
-2\end{array}$ & $\begin{array}{r}-2 \\
-6 \\
-6 \\
+4 \\
0 \\
-4 \\
+2 \\
-1 \\
-1 \\
-1 \\
-4 \\
-1 \\
+5 \\
+2 \\
+3 \\
+1\end{array}$ \\
\hline
\end{tabular}

$F E V_{1}$. - Increases in mean $\mathrm{FEV}_{1}$ were similar after atropine and adrenaline, though there was considerable individual variation. In seven of the eight bronchitics whose pretreatment $\mathrm{FEV}_{1}$ was in the lower three-fifths of their range there was a greater response to atropine than adrenaline. Their mean $\mathrm{FEV}_{1}$ increase with atropine was $36.4 \%$ while with adrenaline it was $15.8 \%$. Nevertheless, in four of the five asthmatics similarly considered there was a greater response to adrenaline. The mean $\mathrm{FEV}_{1}$ increase with adrenaline was $33.7 \%$ compared with $\mathbf{7 \cdot 2} \%$ for atropine. There was no evidence that those responding better to adrenaline than to atropine or vice versa could be paired with either isoprenaline/phenylephrine or salbutamol responders. Salbutamol (2) was significantly superior in bronchodilator action to isoprenaline/phenylephrine $(2)$ and $(6)(P<0.01)$ and was as effective as salbutamol (6). Salbutamol (2) increased the mean $\mathrm{FEV}_{1}$ by $24 \%$.

$F V C$. - The $\mathrm{FEV}_{1}$ and FVC results do not run absolutely parallel, for there is no significant difference between FVC changes in the inhalant groups.

Pulse Rate.-The pulse rate rose significantly with adrenaline and salbutamol $(6)(P<0.01)$, but was unchanged with salbutamol (2) and the isoprenaline/phenylephrine mixture.

$\mathrm{PaO}_{2}$. - The mean oxygen tension was not significantly altered in any treatment group, and the maximum fall was $9 \mathrm{~mm} \mathrm{Hg}$ ( $7 \mathrm{~mm} \mathrm{Hg}$ in the inhalant groups) (Table III). In seven patients in the inhalant groups the oxygen tension fell $5 \mathrm{~mm} \mathrm{Hg}$ or more. In three of the patients the oxygen tension fell more than $5 \mathrm{~mm}$ $\mathrm{Hg}$ after inhalation of isoprenaline/phenylephrine and a similar fall occurred in three patients after salbutamol. Twenty-eight estimations of oxygen tension were carried out in seven patients whose oxygen tension fell $5 \mathrm{~mm} \mathrm{Hg}$ or more following one of the inhalants, and of these estimations 26 showed a fall. However, out of 36 estimations after inhalants in the remaining nine patients only 12 showed a fall. This is a significant difference $(P<0.01)$. When the accepted $\mathrm{FEV}_{1}$ results for each drug are grouped into those with a rise of greater than $20 \%$ and those with no rise or a fall and the changes in oxygen tension are compared, no significant difference is found (Table IV). Nevertheless, there does seem to be a trend after either drug for the $\mathrm{PaO}_{2}$ to rise in the former group and fall in the latter.

$\mathrm{PaCO}_{2}$.- Mean carbon dioxide tension was not significantly altered in any treatment group.

Blood Pressure.-The pulse pressure increased after adrenaline while the mean blood pressure fell. The pulse pressure remained constant after all other treatment.

\section{Discussion}

Despite the many recent papers describing assessments of inhalant bronchodilator therapy, there is still no standard or accepted method for evaluating bronchodilator efficacy. It has long been recognized that the apparent efficacy of a bronchodilator is related to the degree of airways obstruction present before it is administered (Hume and Gandevia, 1957; Hume and Rhys Jones, 1961). This would seem to be a simple relationship, but unfortunately several factors complicate it. Firstly, even starting with the same pretreatment $\mathrm{FEV}_{1}$ level, response to the same dose of bronchodilator can vary from day to day in the same patient. Secondly, improvements of dynamic lung volumes from variable resting values are limited to the maximum levels for the particular subject being investigated. A resting value could in fact be a maximum value. Thirdly, sensitivity to a bronchodilator tends to increase with the $\mathrm{FEV}_{1}$ - that is, the less wheezy the more sensitive. Fourthly, it is difficult at any one time to estimate a maximum value for a particular subject from past experience. Though some variation in response can be accepted when comparison is being made between one group of results and another, provided a sufficient number of results is obtained, it is obviously desirable to keep this variation to a minimum, and some attempt should be made to assess comparability of pretreatment sensitivity to bronchodilatation for the different treatment groups under test.

Many investigators in the past five years have failed to pay any attention to this problem at all and so there is often inadequate evidence to validate their results. Freedman (1971) carried out investigations only when the pretreatment FEV, estimations were "comparable." Others have limited comparison to occasions when airways conductance was within $40 \%$ of the geometric mean of the baseline level (Warrell et al., 1970) or when the pretreatment $\mathrm{FEV}_{1}$ was between 50 and $75 \%$ of the previous highest recording (Choo-Kang et al., 1969).

It is preferable to carry out acute tests of reversal of airways obstruction in as short a period and in as constant an environment as possible, and for this reason studies of comparability are best carried out on inpatients. Though, theoretically, it would be best to wait until a pretreatment $\mathrm{FEV}_{1}$ within a certain range of the value for the previous investigation recurred, for practical reasons it is very difficult to put off a scheduled investigation. Also, the order of treatments is usually randomly allocated to conform to a Latin square pattern, and delay of any one treatment will affect this. Choo-Kang et al. (1969) selected patients whose pretreatment $\mathrm{FEV}_{1}$ was within 50 to $75 \%$ of 
their previous best value, but they did not comment on whether this pretreatment value was maintained during the four days of their investigation. Though these authors mentioned the mean pretreatment $\mathrm{FEV}_{1}$ for each drug under study, neither the range nor the standard deviation for each mean was expressed. Theoretically, it would be possible for one group to consist entirely of $\mathrm{FEV}_{1}$ values at each limit of the group's range of $\mathrm{FEV}_{1}$ and another to be distributed close to the mean with presumably a greater potential for improvement.

Palmer and Diament (1969) and Palmer et al. (1970) calculated their results as a percentage of the predicted normal values, allowing for difference in age, sex, and height. As the comparisons are "within patient" as well as "between patient" studies, this would not seem to be necessary and the effect of expressing results in this way is artificially to minimize bronchodilator efficacy in the patients in the lower $\mathrm{FEV}_{1}$ estimated/predicted range.

We have preferred to consider the potential $\mathrm{FEV}_{1}$ change for any particular patient to be that found during the period of the investigation. When a pretreatment $\mathrm{FEV}_{1}$ fell within the upper two-fifths of this range it has been considered that there was insufficient potential for improvement and these results have been excluded from the analysis of bronchodilator efficacy. The remainder have been analysed for comparability of pretreatment values for each treatment group by a simple scoring system. The disadvantages of this method are, firstly, that the Latin square type of allotment to treatment is interfered with by exclusion of some results, and, secondly, that at the end of the investigation the groups might be found not in fact to be comparable, and the results, accordingly, inconclusive without further extension of the investigation.

\section{PRESENT INVESTIGATION}

This study has shown that for this particular group of patients there was no significant advantage in terms of bronchodilator efficacy of $600 \mu \mathrm{g}$ over $200 \mu \mathrm{g}$ of salbutamol. The only disadvantage of the higher dose of salbutamol was the slight but significant tachycardia, presumably due to some $\beta 1$-adrenergic effect. Tachycardia was not observed at either dose of the isoprenaline/phenylephrine mixture but as a bronchodilator it was less effective than salbutamol. The pharmacological actions of these drugs have already been fully discussed in several recent papers (Choo-Kang et al., 1969; Kelman et al., 1969; Kennedy and Simpson, 1969; Harris, 1970; Hume, 1970; Palmer et al., 1970), but it is important to emphasize that the absence of cardiostimulatory effect is at least theoretically desirable, and salbutamol cannot be completely exonerated. Legge et al. (1971) also showed slight but definite tachycardia after salbutamol and Warrell et al. (1970) found a rise after parenteral salbutamol. We would recommend, therefore, that where possible the dose of inhaled salbutamol be restricted to two puffs.

The fact that some patients seem to derive more benefit from a bigger dose of salbutamol may be merely that they are not very competent at using their inhalers, and Cohen (1971) showed that the "breath-actuated" and "physician-given" methods of administration were superior to the patient-administered method. It would seem better to ensure that patients receive the inhalant in the prescribed dose by accurate inhalation than that the inhaler is used excessively, but inefficiently. Choo-Kang et al. (1969) found a placebo rise of pulse rate at six minutes of $2 \cdot 7 /$ minute and at 20 minutes of $0 \cdot 8 /$ minute. In the present investigation $200 \mu \mathrm{g}$ of salbutamol produced a pulse drop at 20 minutes of $1 \cdot 6 /$ minute and $600 \mu \mathrm{g}$ a pulse rise of $5 \cdot 0 /$ minute. The latter was similar to the rise produced by adrenaline (4.9/ minute) and more than that produced by atropine ( $2.8 /$ minute).

The other possible disadvantage of bronchodilator therapy is that in some of the patients, despite improvement in ventilatory function, arterial oxygen tensions fall. The effect is ascribed to non-selective pulmonary vasodilatation combined with increased cardiac output. Harris (1970) found a fall of over $5 \mathrm{~mm} \mathrm{Hg}$ in between 27.6 and $44.3 \%$ of patients after a variety of bronchodilator drugs. There was, however, no patient in this category in 47 patients to whom isoprenaline/phenylephrine was administered. In the present investigation three of the 16 patients to whom isoprenaline/phenylephrine was administered and three to whom salbutamol was administered showed a fall of over $5 \mathrm{~mm} \mathrm{Hg}$ in oxygen tension. There was no significant difference between the mean falls for the two inhalants.

Patients tended to be consistent in their reaction to bronchodilator therapy and were very likely to show a fall in $\mathrm{PaO}_{2}$ after all forms of therapy if there was a drop of $5 \mathrm{~mm} \mathrm{Hg}$ or more after one. In none was the drop in oxygen tension over $7 \mathrm{~mm} \mathrm{Hg}$ after either salbutamol or isoprenaline/phenylephrine. Changes in oxygen tension could not be related to alterations in $\mathrm{FEV}_{1}$, though Harris (1970) showed a significant increase in $\mathrm{PaO}_{2}$ after isoprenaline/phenylephrine in patients with an $\mathrm{FEV}$, rise of greater than $20 \%$, whom he classed as "responders." In most cases the primary effect of inhalation bronchodilator therapy is to increase the patient's comfort. Salbutamol in a dose of $200 \mu \mathrm{g}$ seemed to do this more effectively than isoprenaline/ phenylephrine and without measurably increased risk.

Our thanks are due to Mrs. P. Rossi for secretarial help. We are grateful to Dr. D. M. Harris, of Allen and Hanbury's Limited, for a financial grant towards equipment.

\section{References}

Altounyan, R. E. C. (1964). Thorax, 19, 406.

Attwood, E. C., Brooks, W., and Leckie, W. J. H. (1970) Thorax, 25, 540 Aviado, D. M., and Schmidt, C. F. (1957). Fournal of Pharmacology and Experimental Therapeutics, 120, 512.

Bass, B. H., Disney, M. E., and Morrison Smith, J. (1969). Lancet, 2, 438. Brittain, R. T., Farmer, J. B., Jack, D., and Simpson, W. T. (1968). Nature, 219,862 .

Chapman, T. T. (1969). British Medical Fournal, 4, 557.

Choo-Kang, Y. F. J., Simpson, W. T., and Grant, I. W. B. (1969). British Medical fournal, 2, 287.

Cohen, B. M. (1962). Current Therapeutic Research, Clinical and Experimental, 4, 601.

Cohen, B. M. (1971). Thorax, 26, 316.

Cohen, A. A., and Hale, F. C. (1965). American fournal of the Medical Sciences, 249, 309.

Crompton, G. K. (1968). Thorax, 23, 46.

Freedman, B. J. (1971). British Medical fournal, 1, 633.

Freedman, B. J., Meisner, P., and Hill, G. B. (1968). Thorax, 23, 590.

Goldfarb, A. A., and Romanoff, A. (1962). Annals of Allergy, 20, 307

Harris, L. H. (1970). British Medical fournal, 4, 579.

Horvath, S. M., and Knapp, D. M. (1954). American fournal of Physiology, 178, 387 .

Hume, K. M. (1970). British Medical Fournal, 1, 173.

Hume, K. M., and Gandevia, B. (1957). Thorax, 12, 276.

Hume, K. M., and Rhys Jones, E. (1961). Quarterly fournal of Medicine, $30,189$.

Kallós, P., and Kallós-Deffner, L. (1963). International Archives of Allergy and Applied Immunology, 24, 17

Kelman, G. R., Palmer, K. N. V., and Cross, M. R. (1969). Nature, 221, 1251

Kennedy, M. C. S., and Simpson, W. T. (1969). British fournal of Diseases of the Chest, 63, 165.

Legge, J. S., Gaddie, J., and Palmer, K. N. V. (1971). British Medical fournal, 1, 637.

Medical Research Council (1965). Lancet, 1, 775.

Palmer, K. N. V., and Diament, M. L. (1969). British Medical Fournal, 1, 31. Palmer, K. N. V., Legge, J. S., Hamilton, W. F. D., and Diament, M. L. (1970). British Medical fournal, 2, 23.

Warrell, D. A., et al. (1970). British Medical fournal, 1, 65.

Zamel, N., Faraco, E. Z., and De Freitas, F. M. (1966). Thorax, 21, 333. 